\title{
Impacts of ICT on the Spatial Differentiation of Social Vulnerability to Natural Hazards in Poland
}

\begin{abstract}
The development of information and communication technologies (ICTs) has significant economic and social impacts at both the global and regional level. Some of these implications have been perceived as positive and unexpected. While both the positive and negative social and economic impacts have been highlighted in the literature, opinions on these impacts remain ambiguous. Those aspects considered to be advantageous include faster communication, ease of use, development in the range of services and revenues, and an increase in individuals' free time allowance. ICT penetrates all branches of the economy as a set of general purpose technologies. New information and communication technologies ease everyday life, serve as tools to help people in extreme situations, e.g. accidents, illnesses or natural disasters, and are also the pillars of contemporary entertainment media. The usefulness of ICT has been stressed and loudly disseminated to a large extent by the media. On the other hand, these new technologies sensitize society in quite new ways to the well-known natural hazards that people have encountered in the past.
\end{abstract}

Keywords

ICT • social vulnerability $\bullet$ natural hazards $•$ electric energy $\bullet$ rebound effect $•$ Poland

(C) University of Warsaw - Faculty of Geography and Regional Studies

\author{
Piotr Werner, Bartłomiej Iwańczak \\ Faculty of Geography and Regional Studies, \\ University of Warsaw, Poland \\ e-mail: peter@uw.edu.pl \\ Faculty of Geography and Regional Studies, \\ University of Warsaw, Poland \\ e-mail: b.iwanczak@uw.edu.pl \\ Received: 1 March 2015 \\ Accepted: 23 November 2015
}

\section{Introduction}

The increasing use of information and communication technologies (ICTs) has vast social and economic implications, both positive and unexpected (it is hard to say they could be negative). The positive economic impacts are highlighted most frequently. Faster communication, ease of use, development in the range of services and revenues, and an increase in individuals' free time allowance are perceived as some of the advantages (Werner 2014). Information and communication media are nowadays commonly seen as a set of general purpose technologies (ICTs), which not only ease everyday life but also serve as a tool to help people in extreme situations e.g. accidents, illnesses or natural disasters. Numerous cases of the usefulness of ICT have been loudly disseminated in the media (via the Internet, radio, newspapers and TV), such as the use of the 112 emergency telephone number (in EU countries), the ability to warn people using a short message service (SMS), as well as issuing either weather or hydrological warnings through Internet services or via TV and radio announcements. The organization of the national warning system in Poland (KSO) primarily use the cellular phone system and a free automatic SMS service (Krajowy System Ostrzegania i Powiadamiania SMS 2015).

These applications are important as the direct front end of ICT services for the public; their importance should not be underestimated, despite the fact that people use them for entertainment purposes nowadays. Computer gaming using mobile $\mathrm{Wi}-\mathrm{Fi}$ devices is another route towards the effective, smooth and faster use of ICT applications, which in turn can be applied to dangerous situations.

Effective methods of communication are seen to be a crucial factor in public security when the appropriate emergency services appear immediately after an emergency call - the monitoring networks allow emergency situations to be processed a priori and the necessary responses can be made. In this way, the resilience of society increases. Logically, it could be said that the social vulnerability to certain natural hazards related to potential extreme natural phenomena should decline. This paper aims to verify the hypothesis that the new multi-directional impacts of the development of ICTs have an influence on social vulnerability to various natural hazards. Some of these impacts significantly upgrade the level of the resilience of society; on the other hand, it is possible to identify some factors which in fact cause an increase in the social vulnerability to natural hazards, both in particular cases and generally, including the ecological footprint of the modern network society (Figure 1).

Taking into account such processes as the speed and manners of information flow which influence the ICT and network society development, the growth in electrical energy consumption, and lifestyle changes in modern society (i.e. the explosion of urbanization, growing mobility and dependence on network services), each of the above-mentioned factors simultaneously causes the upgrade of resilience and, on the other hand, sensitises society in quite new ways to the well- 


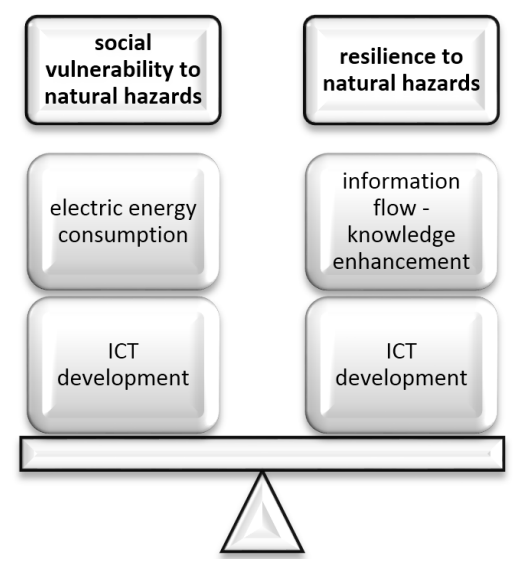

Figure 1. Relationships between ICT development and either social vulnerability or resilience to natural hazards (own elaboration)

known natural hazards that people have encountered in the past. The key factor whose influence is underestimated in the analysis of the mentioned phenomena is people's growing dependency on the electrical energy network supply, which can be treated nowadays as a weak link. An enormous growth in electric energy consumption has been highlighted in households and services both in Poland and across Europe during the last decade.

The relationships between energy consumption and economic growth, and the corresponding policy implications, are widely covered in the economics literature (Payne 2010). Four main economic hypotheses are pointed out in terms of different relations between economic growth and energy consumption:

First, the 'growth' hypothesis asserts that energy consumption plays an important role in economic growth both directly and as a complement to labour and capital in the production process. (...) Second, the 'conservation' hypothesis implies that energy conservation policies, such as the reduction in greenhouse emissions, efficiency improvement measures, and demand management policies, designed to reduce energy consumption and waste may not adversely affect real GDP. (..) Third, the 'neutrality' hypothesis views energy consumption as a small component of real GDP and therefore energy consumption should not have a significant impact on economic growth. (...) Fourth, the 'feedback' hypothesis suggests that energy consumption and real GDP are interdependent and may serve as complements to one another (ibid.p.54).

Aside from the economic factors of growth in energy consumption, the above-mentioned phenomenon of the huge growth of electric energy consumption in households can also be observed. This is a process related to the so-called 'rebound effect', which can be recognised from the past, although in a new form. (Werner 2014).

The rebound effect is defined as growth in consumption as the result of an unintended side-effect of a policy or technological invention aimed at environmental efficiency improvements. Direct and indirect rebound effects have been recognized at the microeconomic level, as well as economy-wide rebound effects touching economic growth and consumption at the macroeconomic level (Maxell \& McAndrew 2011).

Historically, this phenomenon has only been described for the energy sector, and is nowadays known as the Jevons paradox (the so-called 'take-back effect'). "A rebound effect happens when an energy efficient technology is implemented instead of an old one, and when it creates an opposite effect to

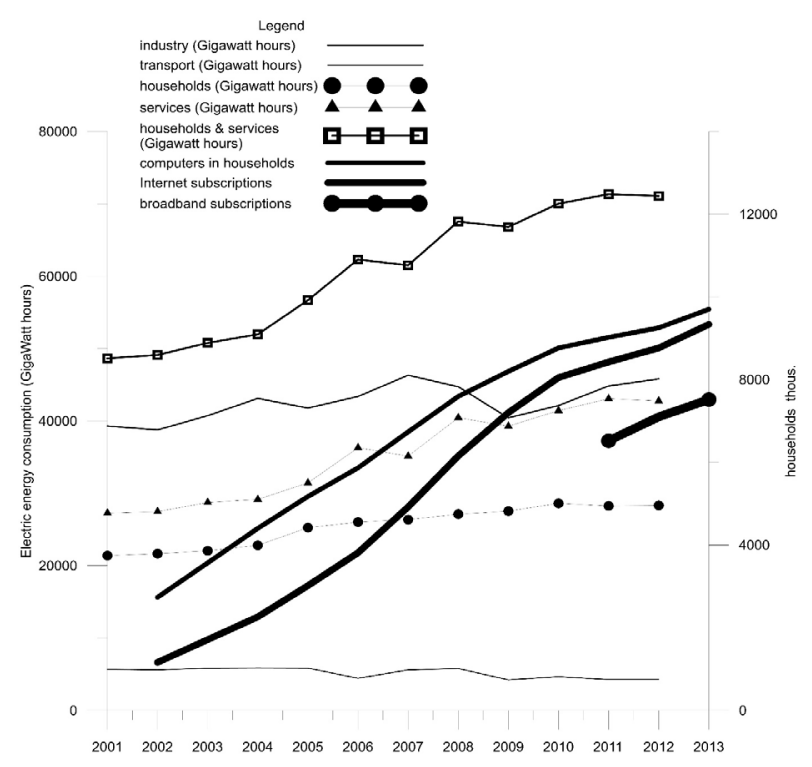

Figure 2. Consumption of electricity by sectors in Poland (Gigawatt hours); Computers, Internet access and broadband subscriptions by households in Poland (own elaboration; source of data: BDL :: Local Data Bank, Central Statistical Office in Poland, 2014, estimation based on Local Data Bank tables)

what could be expected: the new technology does not reduce the total quantity of energy consumed, but increases it. Being more efficient, it cheapens the energy costs and calls for larger uses" (Missemer 2012, p. 98). On the other hand, an analogous phenomenon can be observed in the domain of ICT. The possession of mobile devices causes owners to extend their activity into different situations, exploring their functionality and new networking applications, and occasionally even creating quite new uses for these devices. These are typical take-back effects. Alongside other reasons, one of the direct implications of the increase in ICT use is the rise in electric energy consumption in Poland (Figure 2). Only these aspects are discussed in this study, passing over the other possible factors that result in the increase of electric energy consumption in households and services.

\section{Input data and methodology}

The operationalization of the analysis of these processes involved the selection of available statistical variables representing particular phenomena. The level of development of ICT represented the variables concerning percentages of: households with computers, households with access to the Internet and households with a broadband connection. These variables available at the regional level in Poland are similar to those used in the methodology of the ICT Readiness Index, reflecting the level of networked infrastructure and access to ICT on a global scale (ITU, 2014).

Two sets of data were addressed: the first was acquired from widely accessible official state statistics (which concerned the level of NUTS 2 (Local Data Bank 2015)) and the second was acquired from research conducted within the framework of a social diagnosis of Poland (Diagnoza Społeczna 2015). The detailed cohorts' data were aggregated to the appropriate NUTS level, i.e. counties (powiaty, NUTS 4) and voivodships (NUTS 2). The aim was the verification of the results of the analyses and 


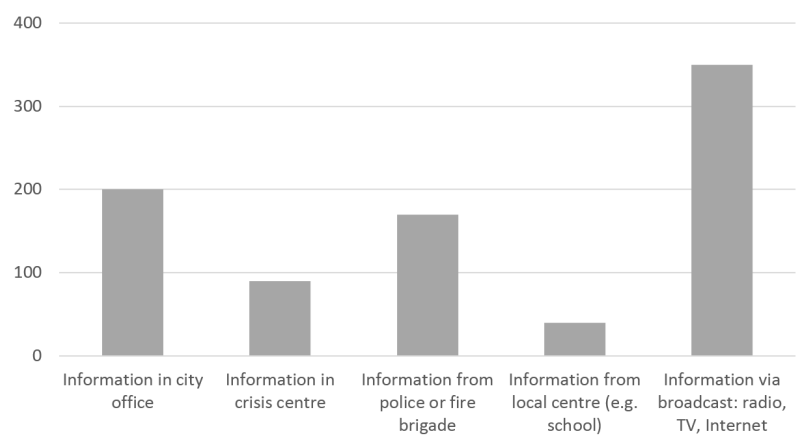

Figure 3. Where people look for information in the event of a natural hazard. Study based on questionnaire (source: Iwańczak 2009)

comparisons using these data independently at different levels of spatial unit aggregation. The data concerning the consumption of electrical energy in households and in the services sector (annual data, GWh) are also available from widely accessible official state statistics at all analysed spatial levels.

The degree of natural hazards in Poland has been evaluated according to official, state statistics as the "expenditures incurred in chapters ${ }^{* * *} 78$ " and concerning "removing the effects of natural disasters" during the period 2008-2013 (annual data) (Local Data Bank 2015), assuming that these data represent real hazards that occurred during this time.

There is a spatial relationship between electric energy consumption in households and services and the level of development of information society indices. Meanwhile, the analogous study concerned the relationship between the consumption of electric energy and the degree of natural hazards. The GWR (Geographically Weighted Regression) method was used, both at the level of NUTS 2 and NUTS 4 . The calculation of spatial weights is based on the common boundaries of spatial units. The weights were construed based on the contiguity of polygon (NUTS unit) boundaries.

An additional analysis was also performed concerning the availability of information on the risk of natural hazards provided by local authority websites.

According to studies, in the event of a natural hazard, the majority of people search for information on what to do via radio broadcasts, TV news and the Internet (Iwańczak, 2009). Subsequently, they will turn to local authority offices, the police and the fire brigade. The last places they seek out current and helpful information are local crisis management centres and schools (as locally-known public centres, Figure 3).

The organizational structure of the crisis management system in Poland involves the national government security centre, sectorial centres and regional centres (at the voivodship level). It is also obligatory for counties to organize local self-government crisis management centres, but this is not so at the commune level. However, citizens have little awareness concerning the functioning of these local headquarters (Figure 3).

The accessibility of information on local potential natural hazards was evaluated using a survey (questionnaire) concerning the content available on local, official websites, using a methodology similar to WAES (the Website Attribute Evaluation System). It was assumed that a random, simple sample should be compared of those websites containing information on natural hazards which occurred in the past and affected the selected spatial units (during recent years, 2008-2013). The survey was conducted between November 2014 and January 2015 by different groups of anonymous students. All groups used the same standardized evaluation form and decided themselves which region they would evaluate. This resulted in an unrestricted random draw, allowing a simple statistical sample to be obtained. Once repeat evaluations of the same websites had been conducted, average values were calculated.

Spatial differentiation of natural hazards in Poland (2008-2013)

The spatial differentiation of natural hazards in Poland was evaluated based on expenditures for removing the effects of natural disasters during the period 2008-2013 (Figure 4).

Several natural disasters affected Poland between 2008 and 2013. According to previously obtained results, the expenditures involved in removing the effects of natural disasters were relatively high, correlated with the theoretical yearly social vulnerability index for extreme weather phenomena $(r=+0.64$, Werner et al. 2015). During this time, the public media reported on all strong winds in the winter seasons and the whirlwinds in the summers of 2008 and 2011, as well as the floods in 2010 and 2011, above all in the southern regions of Poland. The media stressed not only the accidents and (low number of) accidental deaths, and the destruction of houses, roads and agriculture, but above all the breaks in electrical energy supply to households. It is worth noting in fact that nowadays, heating, water and natural gas (which used to be supplied by the network) are managed by individually-installed, computerized devices in households; they only operate when supplied with electric energy from the network. A cut in electric energy usually means a break in supply and the inability to use other household media. This situation can be described as (individual or local) blackout. The duration or frequent repetition of such situations interrupts society's and families' day-to-day lives.

\section{ICT versus consumption of electric energy}

There are a few information society sub-indices which are related to the three recently recognized main processes of ICT development - the dissemination of ICT (computerisation), networking, and the dissemination of broadband. These are: the percentage of owned computers (or mobile devices) in households, the percentage of Internet access, and the percentage of broadband connections in households (the latter can also be classified according to the type of connections used, e.g. mobile PC, wired ADSL or cellular Wi-Fi). The development of ICT in households in Poland and Europe has been described in detail by Werner (2014). There was a significant correlation between Internet access and electric energy consumption in households and services in 2013 ( $r=+0.66$ for households and services, $r=+683$ for households only, using the official state local data bank, Figure 5). Figure 5 presents the relationships between ICT variables, with the dependent variable representing the regional level of electric energy consumption by region (data from NUTS 2, voivodships), analogous to a bubble diagram.

The interpretation of figure 5 proves that regions with higher shares of either broadband connections or Internet access consume more electrical energy. The only exception is the Łódź voivodship, which consumes much more electric energy than its level of ICT development suggests. This situation can be explained by the node location of the crossroads of the main highways in Poland (A1 and A2) and the occurrence of several logistics store investments in this area.

Natural hazards versus ICT and electric energy consumption 


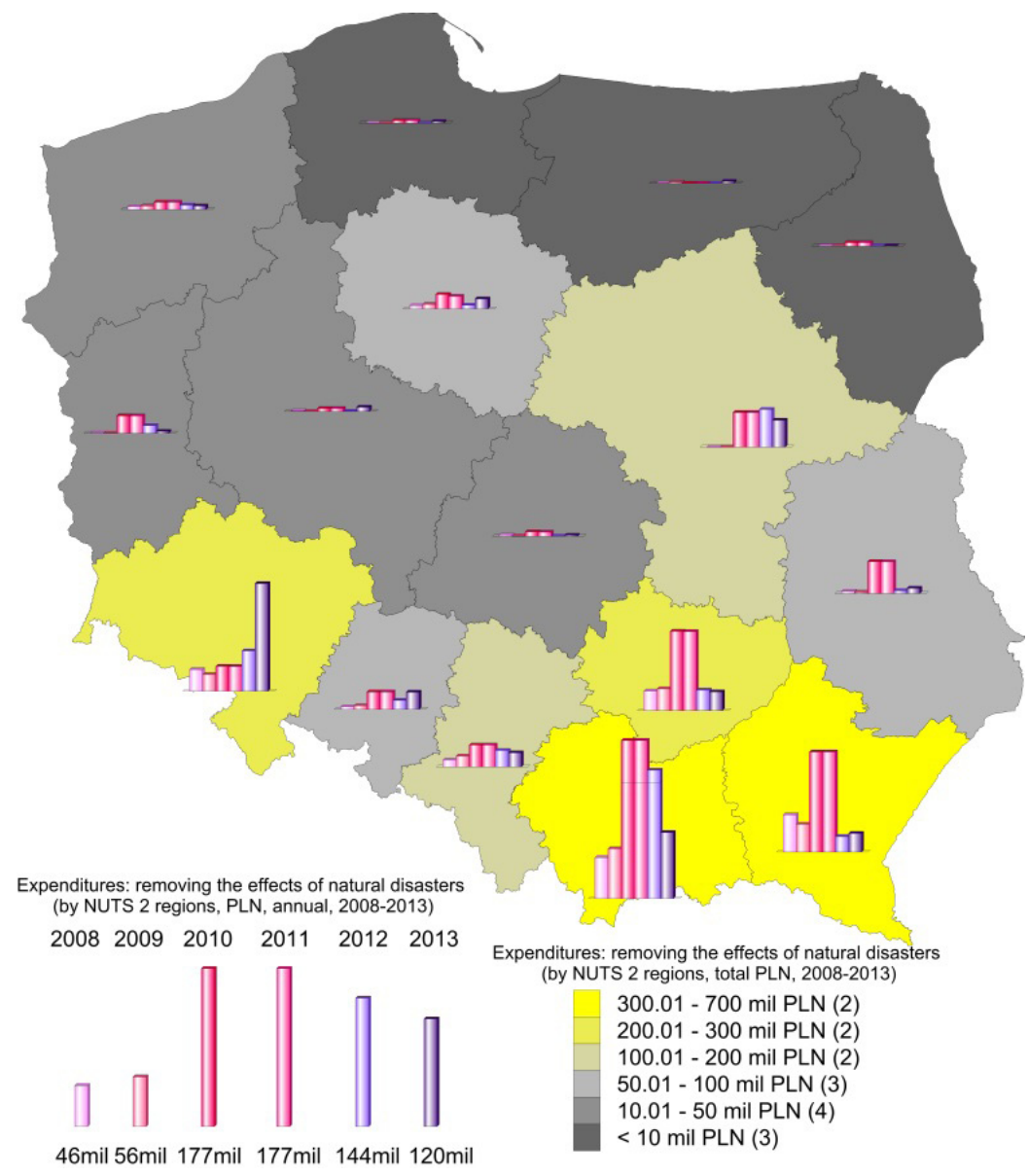

Figure 4. Expenditures for removing the effects of natural diasters by regions (NUTS 2, voivodships) in Poland, $2008-2013$ (own elaboration, source of data: BDL :: Local Data Bank)

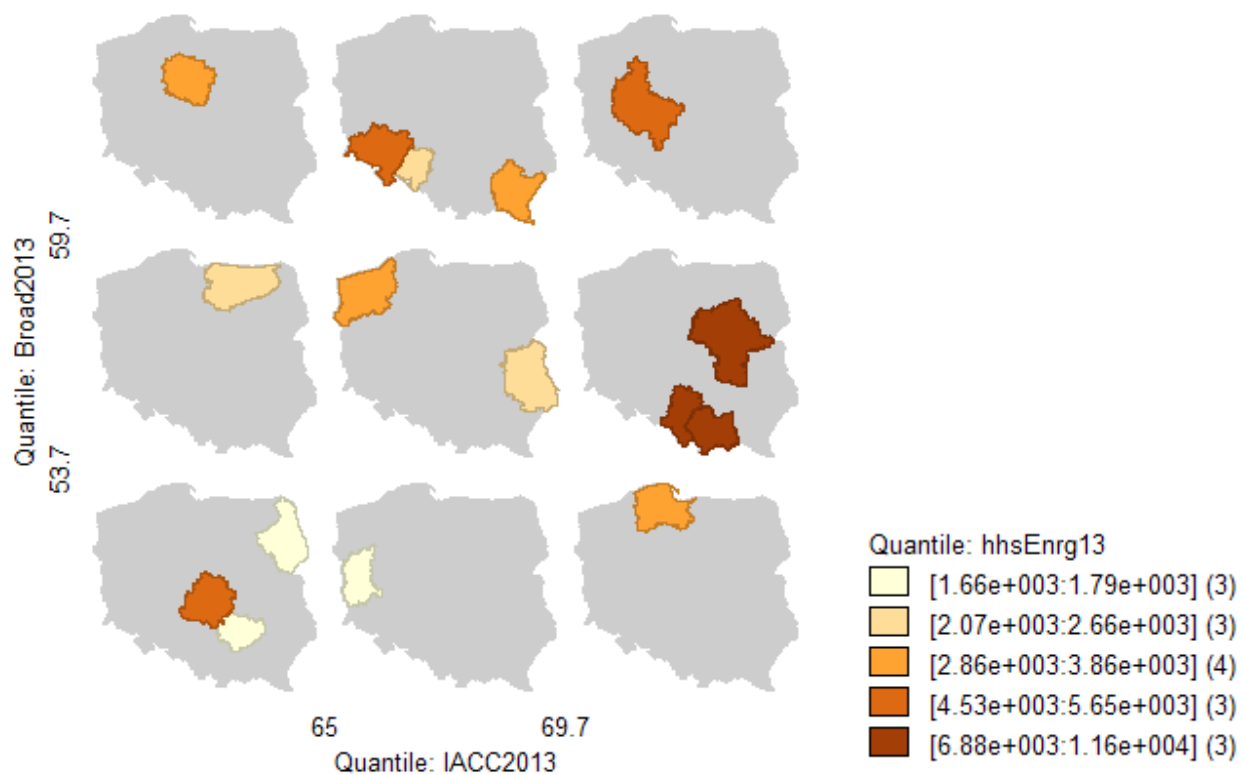

Figure 5. Share of Internet access (IACC) and broadband connections (BROAD) versus consumption of electric energy in households and services (ENRG, Gigawatt hours) in 2013 in Poland; (own elaboration, source of data: BDL :: Local Data Bank) 
MISCELLANEA GEOGRAPHICA - REGIONAL STUDIES ON DEVELOPMENT

Vol. $19 \cdot$ No. $4 \cdot 2015 \cdot$ pp. 64-71 • ISSN: 2084-6118 • DOI: 10.1515/mgrsd-2015-0026

Table 1. Selected results and parameters of statistical and geographically-weighted regression between expenditures for removing the effects of natural disasters (dependent variable) and sub-indices of ICT development and level of consumption of electric energy (independent variables) by NUTS 2 and 4 regions in Poland (2012-2013, software GeoDa, SPSS, source of data $B D L$ :: Local Data Bank, Polish Central Statistical Office and research project data "Diagnoza Społeczna - Zintegrowana Baza Danych", Social Diagnosis of Poland)

\begin{tabular}{|c|c|c|c|c|c|c|c|c|c|}
\hline No & Model & Year & Independent variables & $\begin{array}{l}\text { Dependent } \\
\text { variable }\end{array}$ & $\begin{array}{c}\mathbf{R} \\
\text { coeff. }\end{array}$ & $\begin{array}{c}\mathbf{R}^{2} \\
\text { coeff. }\end{array}$ & $\begin{array}{l}\text { NUTS } \\
\text { level }\end{array}$ & $\begin{array}{l}\text { Source of } \\
\text { ICT data }\end{array}$ & Remarks \\
\hline 1 & statistical & 2012 & $\begin{array}{c}\text { SGWh, HGWh, BROAD, } \\
\text { PC, IACC }\end{array}$ & $\mathrm{NHE}$ & 0.54 & 0.292 & 2 & $\begin{array}{l}\text { Local data } \\
\text { bank }\end{array}$ & $\begin{array}{c}\text { shares of } \\
\text { households } \\
\text { (BROAD, PC, } \\
\text { IACC) }\end{array}$ \\
\hline 2 & statistical & 2013 & $\begin{array}{c}\text { SGWh, HGWh, BROAD, } \\
\text { PC, IACC }\end{array}$ & $\mathrm{NHE}$ & 0.474 & 0.225 & 2 & $\begin{array}{l}\text { Local data } \\
\text { bank }\end{array}$ & $\begin{array}{c}\text { shares of } \\
\text { households } \\
\text { (BROAD, PC, } \\
\text { IACC) }\end{array}$ \\
\hline 3 & statistical & 2012 & $\begin{array}{c}\text { SGWh, HGWh, PC, } \\
\text { MobilePC, IACC, } \\
\text { WireADSL, TRZEPAK, } \\
\text { CellWiFi, CellModem, } \\
\text { AvgInternet }\end{array}$ & $\mathrm{NHE}$ & 0.94 & 0.883 & 2 & $\begin{array}{c}\text { Social } \\
\text { diagnosis }\end{array}$ & $\begin{array}{l}\text { Aggregated } \\
\text { cohort's data of } \\
\text { ICT indices }\end{array}$ \\
\hline 4 & statistical & 2012 & $\begin{array}{l}\text { TGWh, Avglnternet, IACC, } \\
\text { PC, MobilePC, WireADSL, } \\
\text { TRZEPAK, CellWiFi, } \\
\text { CellModem, DialUp } \\
\end{array}$ & $\mathrm{NHE}$ & 0.333 & 0.111 & 4 & $\begin{array}{c}\text { Social } \\
\text { diagnosis }\end{array}$ & $\begin{array}{l}\text { Aggregated } \\
\text { cohort's data of } \\
\text { ICT indices } \\
\text { All counties }\end{array}$ \\
\hline 5 & statistical & 2012 & $\begin{array}{l}\text { TGWh, Avglnternet, IACC, } \\
\text { PC, MobilePC, WireADSL, } \\
\text { TRZEPAK, CellWiFi, } \\
\text { CellModem, DialUp }\end{array}$ & $\mathrm{NHE}$ & \multicolumn{2}{|c|}{$\begin{array}{l}\text { No valid } \\
\text { observations } \\
\text { of dependent } \\
\text { variable }\end{array}$} & 4 & $\begin{array}{c}\text { Social } \\
\text { diagnosis }\end{array}$ & $\begin{array}{l}\text { Aggregated } \\
\text { cohort's data of } \\
\text { ICT indices } \\
\text { City (urban) } \\
\text { counties } \\
\end{array}$ \\
\hline 6 & GWR & 2012 & $\begin{array}{c}\text { SGWh, HGWh, PC, } \\
\text { MobilePC, IACC, } \\
\text { WireADSL, TRZEPAK, } \\
\text { CellWiFi, CellModem, } \\
\text { Avglnternet }\end{array}$ & $\mathrm{NHE}$ & 0.798 & 0.636 & 2 & $\begin{array}{c}\text { Social } \\
\text { diagnosis }\end{array}$ & $\begin{array}{l}\text { Aggregated } \\
\text { cohort's data of } \\
\text { ICT indices }\end{array}$ \\
\hline 7 & GWR & 2013 & $\begin{array}{l}\text { PC, IACC, BROAD, } \\
\text { HGWh, SGWh }\end{array}$ & $\mathrm{NHE}$ & 0.494 & 0.244 & 2 & $\begin{array}{l}\text { Local data } \\
\text { bank }\end{array}$ & $\begin{array}{c}\text { shares of } \\
\text { households } \\
\text { (BROAD, PC, } \\
\text { IACC) }\end{array}$ \\
\hline
\end{tabular}

NHE - expenditures for removing effects of natural disasters, SGWh - electric energy consumption by services (Gigawatt hours), HGWh - electric energy consumption in households (Gigawatt hours), TGWh - total energy consumption in all sectors (Gigawatt hours), BROAD - broadband connections, PC - computers in households, IACC - Internet connections, MobilePC - mobile devices in households, WireADSL - ADSL Internet broadband connections, TRZEPAK - LANs in households, CellWiFi - wireless cellular Internet links, CelIModem - wireless cellular Internet modem links, AvgInternet - average Internet speed.

The evaluation of the relationship between natural hazards (represented by expenditures for removing the effects of natural disasters) and the level of development of ICT, in conjunction with electric energy consumption, has been studied using a statistical and a geographically-weighted linear regression model independently for three sets of data collected on ICT: from the official state local data bank (for NUTS 2 regions), and from social diagnosis for NUTS 2 and NUTS 4 regions. These comparisons were made in order to confirm the relationships and assumed hypothesis. The remaining variables were acquired from the official statistical local data bank. A comparison of the results is presented in table 1 (Figure 6 ).

Figure 6 presents the relationship between Internet access and the consumption of electric energy in households and services, with the dependent variable representing the level of electric energy consumption by region (data from NUTS 2, voivodships), analogous to a bubble diagram.
The interpretation of figure 6 proves that the most highly populated regions (voivodships) in Poland (Mazovia, Greater Poland, Lesser Poland, Upper and Lower Silesia), which consume the most electric energy and are characterized as having the highest levels of ICT development (Internet access), faced the greatest number of natural hazards between 2008 and 2013. Over the same period, two of the less developed regions (the Opole and Holy Cross voivodships) faced a similar level of hazards.

The geographically-weighted regression between expenditures for removing the effects of natural disasters (dependent variable) and ICT sub-indices, in conjunction with electric energy consumption by NUTS 4 regions (counties), is not significant (the results are below the threshold of confidence level). It is impossible to evaluate the urban counties because there was no occurrence of expenditures (dependent variable) in this subset in 2012 (data for NUTS 4, acquired from the "social diagnosis study" (Diagnoza Społeczna 2014) in 2012). 


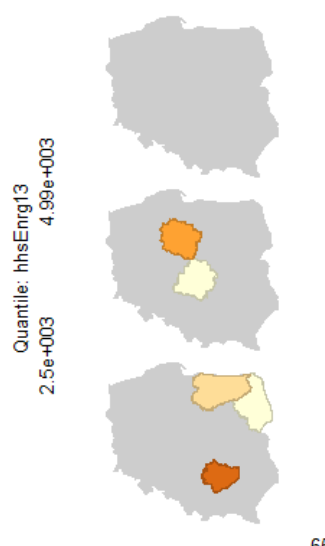

65
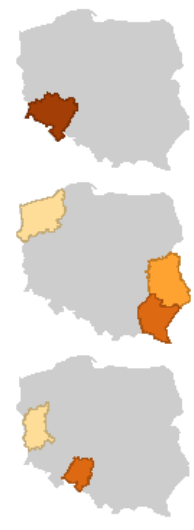

Quantile: IACC2013

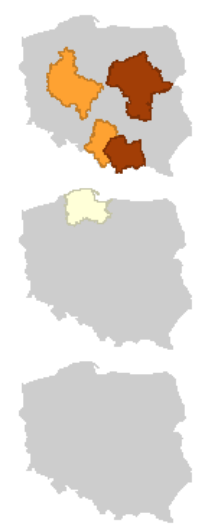

69.7
Quantile: totalNH13

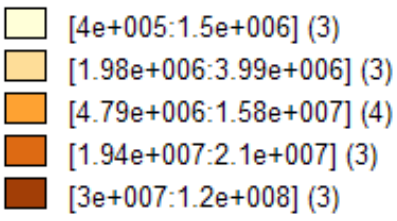

Figure 6. Share of Internet access (IACC) and consumption of electric energy in households and services (ENRG, Gigawatt hours) versus expenditures for removing the effects of natural disasters (totalNH13, Polish currency PLN) in 2013 in Poland (own elaboration, source of data: BDL :: Local Data Bank)

Table 2. Statistics from the survey of regional websites. Evaluation of information concerning natural hazards on local authorities' websites: basic contact information (SumA), content (SumB), accessibility (SumC) and overall score (SumABC)

\begin{tabular}{|c|c|c|c|c|c|c|}
\hline \multicolumn{9}{|c|}{ Statistics } \\
\hline Parameters & N & Difference & Minimum & Maximum & Average & Std.Dev. \\
\hline SumA (max 27 pts) & 70 & 26 & 0 & 26 & 10.5 & 7.3 \\
\hline SumB (max 27 pts) & 70 & 27 & 0 & 27 & 6.0 & 6.3 \\
\hline SumC (max 27 pts) & 70 & 23 & 3 & 26 & 14.9 & 6.0 \\
\hline SumABC (max 81 pts) & 70 & 68 & 6 & 74 & 31.4 & 15.7 \\
\hline
\end{tabular}

Potential usefulness of ICT in upgrading a society's coping capacity for natural hazards

The common opinion on the usefulness of ICT, in relation to looming natural hazards, stems from the belief that information on possible natural hazards is broadcast simultaneously on the Internet, TV news and radio and can be transmitted to people in danger almost immediately. There is also a reverse aspect to this situation. Basic ICT elements - mobile devices and wired hardware - require electric energy, which is being consumed more and more, and most of all in urban areas. There is a need to provide the information of possible threats and natural hazards long enough in advance to allow people to prepare themselves before the hazardous event occurs. The roles of TV and radio are invaluable in this situation, but only in the short- and mediumterm, and the information provided usually covers basic aspects of the potential immediate actions to be undertaken.

Nowadays, the Internet is the main medium which can provide information long enough in advance of possible natural hazards. This communication should take the form of websites authorized by official, local or regional authorities. They should provide appropriate and comprehensive information on natural hazards and ways to prepare for the types of disasters that have affected their regions in the past. According to the study mentioned above, in the event of natural hazards, people initially look to the national public media for information, and secondly to local media. As such, these bodies should be involved in the local public e-services, at least in terms of providing contact information.
The evaluation of such Internet content available on local and official websites was conducted using a methodology similar to WAES (the Website Attribute Evaluation System). The index selected was the percentage of basic public e-services accessible on the Internet which cover the topic of natural hazards. Applying this methodology requires the explicit testing of each attribute. The scale was fairly equally divided between the existence and non-existence of information concerning natural hazards for each website.

The evaluation concerned three main threads exposed in the questionnaire: basic contact information (part A), content (part B) and accessibility (part C). An overall ranking concerning the questionnaire was also applied. The sum of ranks in the three categories showed the final ranking position.

In total, 109 websites of local authority spatial administrative units (communes and counties) were evaluated. Of these websites, 70 were scored, since 39 of them contained no information concerning natural hazards. The maximum possible obtainable score was 81 points (each part contributed 27 points). The spatial distribution of the evaluated regions is presented in figure 7 .

Looking at the spatial distribution of the evaluated websites, there is a differentiation of information quality, completeness (part A), and contents (part B), which are rather closely related and tend to coexist (if they exist at all). Accessibility (part $\mathrm{C}$ ) is weaker and its impact on the overall score is smaller. The spatial distribution of these selected regions (assumed to be random), when tested against the Moran Index (Moran I = 0.034), showed 


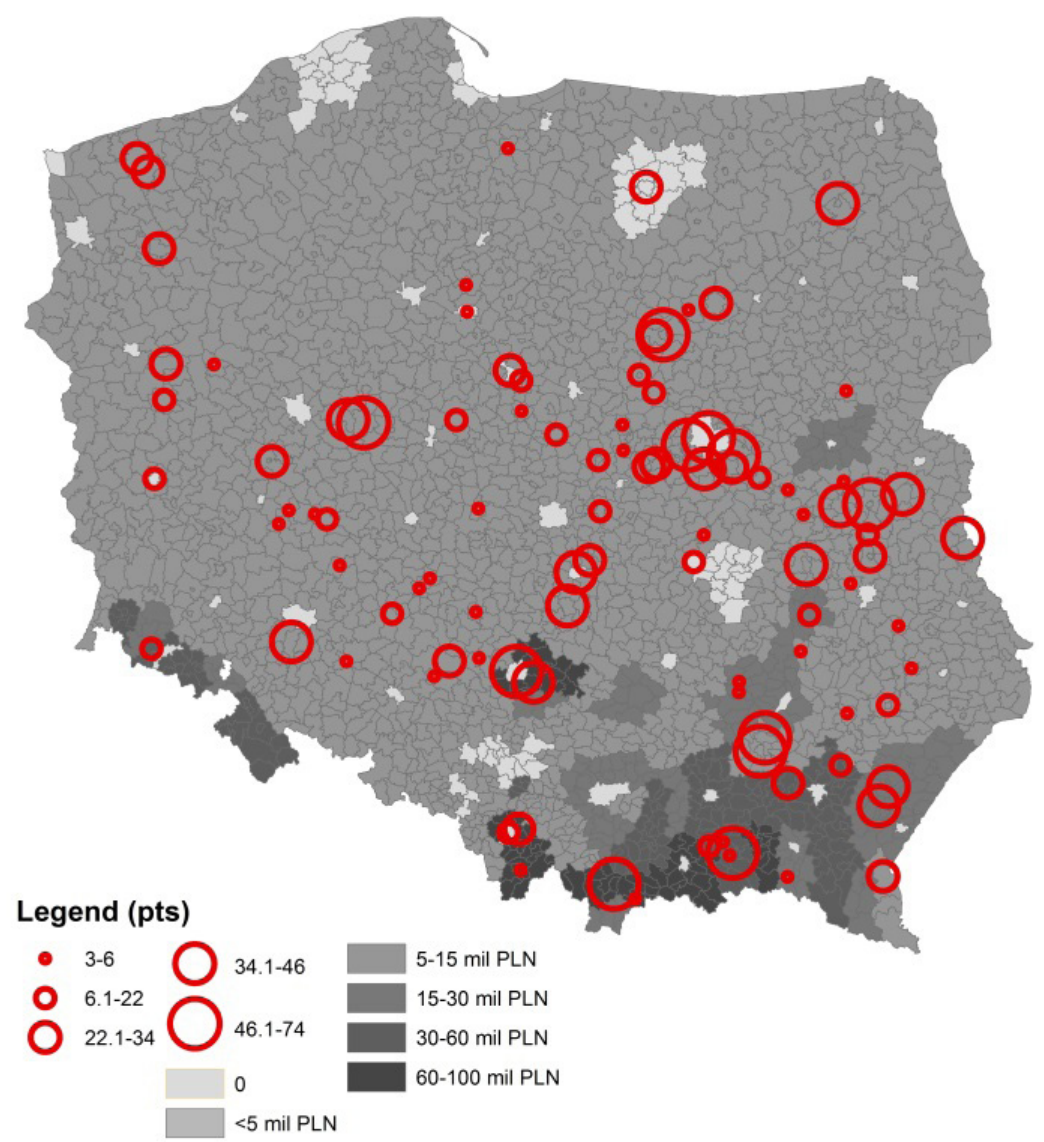

Figure 7. Statistics from the survey of regional websites (random simple sample). Evaluation of information concerning natural hazards on local authority websites (pts) versus sum of expenditures for removing the effects of natural disasters in Poland (2008-2013) by NUTS 4 (counties, own elaboration based on questionnaires)

that, given the z-score of 2.94 , there is a less than $1 \%$ likelihood that this clustered pattern could be the result of random chance. No random pattern was obtained and the survey is not spatially representative for the whole set of regions in Poland. On the other hand, a one-sample nonparametric test sequence for randomness (Runs test, using SPSS) proved that the null hypothesis should be rejected and the sample is not a random draw. However, this is the first step in the evaluation of information flow - knowledge enhancement via information on natural hazards disseminated by the local authorities of spatial administrative units.

\section{Conclusions}

Despite the lack of representativeness of the evaluation of websites for the whole of Poland, and the inability to evaluate the impact of certain information society sub-indices on the spatial differentiation of vulnerability to natural hazards (due to the lack of appropriate data), some other achievements of the study are worth highlighting. The verification of the main hypothesis concerning the direct relation between expenditures for removing the effects of natural disasters and electric energy consumption is not straightforward for all the levels of administrative division (Table 1). Despite the other factors, an indirect two-way relationship is revealed between the level of development of the information society and the vulnerability to (at least a subset of) natural hazards. The relationship has two aspects: on the one hand, ICT has a direct impact on the speed and volume of information flow and knowledge enhancement, which create the conditions to raise the social resilience to natural hazards. On the other hand, the hidden link is electric energy consumption, which is growing rapidly nowadays in households and the services sector (not only in Poland but across the whole of Europe). This phenomenon sensitises society, which comes to depend more and more on a working infrastructure powered by and reliant on a continuous supply from the electric energy network. This is an effect of the so-called 'rebound effect', which has been proved for ICT applications and implies this take-back effect of electric energy consumption. Complex relations exist between the factors highlighted above. They may be treated as independent targets of energy and information society policies, but at the same time these factors are interdependent phenomena. Rebound effects should also be included in the development costs of ICT to gain common advantages i.e. increase in quality of life, easier social communication, and better, new goods and services which facilitate daily life and work. The dynamics of ICT dissemination is becoming the most important factor in changes in the consumer behaviour of individuals and the whole technical culture of societies (Werner 2014).

\section{Acknowledgment}

The research project, 'Spatial Differentiation of Information Society Vulnerability to Defined Environmental Hazards in Poland' is supported by the Polish National Science Centre (DEC-2011/03/B/HS4/04933, 2012-2015). 


\section{References}

BDL, Local Data Bank. Available from: <http://stat.gov.pl/bdlen/ app/strona.html?p_name=indeks>. [15 January 2015].

Diagnoza Społeczna zintegrowana baza danych. Available from: <http://www.diagnoza.com/>. [15 October 2014].

Iwańczak, B 2009, Perception of risk flooding in Łomianki County, M.Sc. thesis, University of Warsaw.

Krajowy System Ostrzegania i Powiadamiania SMS. Available from: <http://kso.pl/>. [15 January 2015].

ITU, 2014, Measuring the Information Society Report 2014, ITU, Geneva Switzerland.

Maxwell, D, Owen, P, McAndrew. L, Muehmel, K \& Neubauer, A 2011 Addressing the Rebound Effect, a report for the European Commission DG Environment, 26 April 2011. Available from: <http://ec.europa.eu/environment>. [3 July 2015]
Missemer, A 2012, 'William Stanley Jevons The coal question (1865), beyond the rebound effect', Ecol. Econ. vol. 82, pp. 97-103.

Payne, JE 2010, 'Survey of the international evidence on the causal relationship between energy consumption and growth', Journal of Economic Studies vol. 37, pp. 53-95. DOI: $10.1108 / 01443581011012261$

Werner, P 2014, 'The rebound effect of information and communication technologies development in the European Union', Appl. Spat. Anal. Policy, pp. 1-15. DOI:10.1007/ s12061-014-9125-z

Werner, P, Kowalewski, M \& Korzeniecki, P 2015, 'Integrated assessment of social vulnerability to defined weather hazards in Poland', Pr. Stud. Geogr., vol 57, pp 89-101. 